NBER WORKING PAPER SERIES

\title{
INTERPERSONAL EFFECTS IN CONSUMPTION: \\ EVIDENCE FROM THE AUTOMOBILE PURCHASES OF NEIGHBORS
}

\author{
Mark Grinblatt \\ Matti Keloharju \\ Seppo Ikaheimo \\ Working Paper 10226 \\ http://www.nber.org/papers/w10226 \\ NATIONAL BUREAU OF ECONOMIC RESEARCH \\ 1050 Massachusetts Avenue \\ Cambridge, MA 02138 \\ January 2004
}

We would like to thank the Finnish Vehicle Administration and the Finnish Tax Administration for providing access to the data and the Office of the Data Protection Ombudsman for recognizing the value of this project to the research community. Our appreciation also extends to Juhani Linnainmaa and Antti Lehtinen, who provided superb research assistance, to Ivo Welch, who generated many insights that benefited this paper. Seminar participants at Berkeley, Columbia University, and the University of Southern California, as well as Shlomo Benartzi, Markku Kaustia, and Mark Weinstein, offered helpful comments on earlier drafts. Financial support from the Academy of Finland, Foundation for Economic Education, and Paulo Foundation is gratefully acknowledged. The views expressed herein are those of the authors and not necessarily those of the National Bureau of Economic Research.

(C)2003 by Mark Grinblatt, Matti Keloharju, and Seppo Ikaheimo. All rights reserved. Short sections of text, not to exceed two paragraphs, may be quoted without explicit permission provided that full credit, including (C) notice, is given to the source. 
Interpersonal Effects in Consumption: Evidence from the Automobile Purchases of Neighbors Mark Grinblatt, Matti Keloharju, and Seppo Ikaheimo

NBER Working Paper No. 10226

January 2004

JEL No. D1, D8

\begin{abstract}
$\underline{\text { ABSTRACT }}$
This study analyzes the automobile purchase behavior of all residents of two Finnish provinces over several years. It finds that a consumer's purchases are strongly influenced by the purchases of his neighbors, particularly purchases in the recent past and by neighbors who are geographically most proximate. There is little evidence that emotional biases, like envy or an urge to conform, lie behind the interpersonal influence in automobile consumption. The most reasonable alternative explanation for these findings is some form of information sharing among neighbors.

Mark Grinblatt

UCLA

Anderson Graduate School of Management

110 Westwood Plaza

Los Angeles, CA 90095-1481

and NBER

mark.grinbaltt@anderson.ucla.edu

Matti Keloharju

Helsinki School of Economics

Department of Accounting and Finance

Runeberginkatu 22-24

FIN-00100 Helsinki, Finland

matti.keloharju@hkkk.fi

Seppo Ikaheimo

Helsinki School of Economics

Department of Accounting and Finance

Runeberginkatu 22-24

FIN-00100 Helsinki, Finland

seppo.ikaheimo@hkkk.fi
\end{abstract}




\section{Introduction}

Mainstream economists have long debated the role that interpersonal effects should play in the theory of consumption. Alfred Marshall's Principles of Economics, the $19^{\text {th }}$ century synthesis of neoclassical economics, makes no reference to interpersonal effects, yet Marshall himself seemed to recognize the existence of such effects in his speeches and was chided by Thorstein Veblen (1898) for failing to acknowledge them in his analytical writings. Friedman's (1957) classic treatise on consumption rejects interpersonal effects as a determinant of consumption yet noteworthy contemporaries of Friedman, such as Morgenstern (1948) and Stigler (1950), and subsequent generations of economists have argued that such effects exist. ${ }^{1}$

This paper is an empirical investigation into whether interpersonal effects exist in the consumption of a particularly important commodity — automobiles — and if so, what accounts for the effects. Information economics and behavioral economics now represent two of the most popular branches of economic thought and interpersonal influences can be accounted for by each of these subfields. We will analyze which of these two branches of economic thought best explains any interpersonal effects found in the consumption of automobiles. This may help assess the relative theoretical import of these subfields in areas of economics where interpersonal influences play a key role.

\footnotetext{
${ }^{1}$ A number of economists have taken on the challenge of developing theoretical models of interpersonal effects in consumption. Leibenstein (1950) developed models of snob, bandwagon, and Veblen effects in consumption. Duesenberry's (1949/1962) relative income hypothesis argued that consumption is a function of where the consumer lies in the income distribution, the degree to which others (particularly his contacts) are consuming, and habit formation. More recent work by Becker (1974), Pollack (1982) and Robson (1992), and in the asset pricing literature by Abel (1990), Gali (1994), Campbell and Cochrane (1999), and Chan and Kogan (2002), extend this idea. Fads and conformity have been modeled in Bikhchandani, Hirshleifer, and Welch (1992), Bernheim (1994), and Pesendorfer (1995), among others, and Veblen effects have been the outcome of a wealth signaling model developed by Bagwell and Bernheim (1996).
} 
For our purposes, it is important to define what we mean by an interpersonal effect that is generated by information versus behavior. The appropriate categorization is distinguished by the modus operandi of the influence: Information economics accounts for interpersonal effects when the consumption of others is taken as evidence about the reality of the consumed good, and helps to resolve uncertainty about the intrinsic utility obtained upon purchase. This may include information about the quality of the good, but it may also include information about its resale value or the price that will be paid for the purchase. Behavioral economics accounts for the effect when the influence of the consumption of others is driven by a psychological need to conform to (or rebel against) the social expectations of others. ${ }^{2}$ Motives like envy, conformity, or snobbery come to mind here.

Information models comprise a very broad category. Models of the rational expectations variety, for example, where the observed actions of consumers reveal the quality of a good, clearly fall within the information realm. Such models also fit comfortably as extensions of the neoclassical tradition. In static information models, the actions of all consumers are informative if each consumer has private information, and often, equilibrium prices become sufficient statistics for the private information of all consumers. In dynamic information models that exhibit sequentiality, the actions of a few can generate herd behavior that is fully rational. For example, in Bikhchandani, Hirshleifer, and Welch (1992), private information is not used once a cascade is attained. The end result is conformity, but of a type that is driven by the implicitly communicated information of the few early entrants to a decision queue, not by an emotional fad. Price search models, as in Fishman (1992), also fall within this category. Here, the benefits from the acquisition of information are weighed against the cost of information gathering.

\footnotetext{
${ }^{2}$ This dichotomous classification is similar to a classification found in the psychology literature. See Deutsch and Gerard (1955).
} 
Models where consumers "Keep up with the Joneses" for emotional reasons, in the tradition of Duesenberry (1949/1962), fall within the behavioral category. This is a modest twist on Thorstein Veblen's (1899/1931) sociological analysis of the origins of consumer preferences. Veblen's The Theory of the Leisure Class postulated that upper classes would try to distinguish themselves from the lower classes by consuming luxury goods. The lower classes would try to emulate this behavior. The motive for this emulation is behavioral in that it is unrelated to the intrinsic utility of the good itself.

Economics, in the last few decades, has burst forth with theoretical models in both directions. How does one know which direction is appropriate without empirical analysis of interpersonal effects? Moreover, how does one even counter Friedman's contention that efforts to model interpersonal consumption effects are misguided, unless the field has undertaken careful empirical analyses to document that such effects exist?

Because of the lack of data, it has been difficult to address the issue of interpersonal effects in the consumption function. Akerlof (1998, p. 1007) perhaps best sums up what numerous authors have observed - that statistically significant neighborhood effects are difficult to interpret when there are neighborhood fixed effects. Thus, interpersonal effects are not validated by observing that a group of neighbors purchase similar baskets of goods or have similar savings rates. Obviously, omitted variables may underlie the attributes that account for these similarities in consumption. Data, even at the zip code level, cannot eliminate such fixed effects. Now, however, a dataset on Finnish automobile consumption, consumer location, and consumer attributes allows us to implement a test of interpersonal effects in consumption with both extraordinary sample sizes and controls.

In this paper, we test whether interpersonal consumption effects exist and have a geographic component by studying whether neighbors influence the automobile consumption 
choice. In doing this we are able to control for numerous common attributes that might account for the findings. We also are able to analyze the source of the influence - that is, whether neighbor-influenced preferences for automobiles are driven by informational or behavioral considerations.

The consumption of automobiles in Finland represents an ideal testing ground for understanding interpersonal effects on consumption. First, automobiles represent highly visible consumption, and thus offer a great opportunity to uncover a behavioral social influence. Automobile consumption (along with housing) was used by Duesenberry (1949/1962) as an example of how behavioral interpersonal effects influence consumption. He wrote,

"What kind of reaction is produced by looking at a friend's new car? The result is likely to be a feeling of dissatisfaction with one's own ... car. (The dissatisfaction) ... will lead to an increase in expenditure.

Automobile consumption is also used as an example of publicly visible consumption in literatures outside of economics. ${ }^{3}$ Goods that are privately consumed, like mattresses or medicines, do not offer the same opportunity for addressing this aspect of interpersonal influence on consumption. Second, for many of the subjects in our study, automobiles are a luxury rather than a necessity, and luxury goods should have more interpersonal effects than other goods as the scant empirical evidence on interpersonal effects recognizes. ${ }^{4}$ In contrast to the U.S., most of the subjects studied have access to high quality public transportation, and the tax rate on a typical automobile (nearly 50\%) and its fuel (about 70\%) makes its acquisition and use very costly. Finally, Finland collects data on a remarkably large number

\footnotetext{
${ }^{3}$ See, for example, Bourne (1957), Bearden and Etzel (1982), Solomon (1999), and Peter and Olson (2001).

${ }^{4}$ For example, Basmann, Molina, and Slottje (1988) found that durables (luxury goods) had the highest marginal rate of substitution elasticities of any commodity group.
} 
of useful control variables. All of this makes Finnish automobile consumption ideally suited for our purposes.

Using logit regressions on all consumers in the most heavily populated provinces in Finland, we find that neighbors who purchase a car, particularly those who purchased recently and are nearest in distance, increase the propensity of a consumer to purchase a car. This effect exists controlling for the age, income, employment status, home ownership, marital status, dependents, commuting costs, and sex of the consumer, as well as observable and unobservable variables that are common to a larger community. The neighborhood effect is also strongest within the lowest social classes, particularly if the neighbor exerting the influence is of the same social class or a higher social class.

The effects are stronger and in the same direction when we analyze logit regressions for purchases of particular car makes and models. That is, a near neighbor's purchase of a Honda (or some other make) has an even more significant influence on the decision of a consumer to buy a Honda (or that other make). The influence is stronger still if we are talking about Honda Accords or other specific models. This effect is highly significant even controlling for the general propensity of a neighborhood to buy Hondas (or Accords). It also is more pronounced for used cars and for the most recent purchases by neighbors. Such evidence more strongly favors the hypothesis of information dissemination among neighbors as the primary source of the interpersonal consumption influence.

In addition, we find that these neighborhood effects and social class effects do not operate in the manner that some behavioral theorists suggest. Some theorists, like Veblen, have suggested that social classes above one's own should have the greatest influence. That is, keeping up with the Joneses is more important if the Joneses are richer than you are. Our findings suggest that the Joneses are most important for influencing a consumer if they are of 
the same social class as the consumer and that same class emulation is less prevalent among the higher social classes and among new car buyers. We are unaware of any behavioral theories that are consistent with these findings.

Our results are organized as follows: Section 2 describes the data and the empirical methodology. Section 3 presents the results, beginning with summary statistics before introducing an extensive series of logit regressions. Section 4 concludes the paper with a brief summary of our findings.

\section{Data and Methodology}

We analyze variables derived from the union of two datasets: One is a data set on automobile ownership and purchases. Another is a dataset based on the income tax returns of residents of two provinces of Finland.

\subsection{Automobile Ownership and Purchase Data}

Data on automobile purchases and ownership were obtained from the Finnish Vehicle Administration (FVA). The dataset records the type of personal automobile owned by each car-owning resident on June 10, 2002 for all purchases made prior to 2002, the exact date the automobile was purchased, and registration data that allow us to infer whether the purchase was of a used or new vehicle. ${ }^{5}$ (Purchases of trucks, buses, and related commercial vehicles are excluded.) The data are comprehensive for residents in the provinces of Uusimaa and East Uusimaa. These provinces contain Greater Helsinki and represent the most densely populated areas in Finland.

\footnotetext{
${ }^{5}$ The FVA dataset contains only the most recent purchase of a car. Few purchases in the January 1,1999 through December 31, 2001 sample period we focus on are missing because of the typically lengthy periods over which Finnish residents tend to own the same car. In the rare instance that a person has bought more than one car in a single year, we consider only the most recent purchase in that calendar year.
} 
The dataset is primarily used to analyze car purchase behavior between January 1, 1999 to December 31, 2001. Car purchases prior to January 1, 1999 are used to assess the degree to which purchases over the three year interval were influenced by the 5-year history of car purchases (or nonpurchases) of each subject's neighborhood.

\subsection{Tax Authority Data}

Our analysis develops a set of explanatory variables from Finnish tax return data, which we linked to the FVA dataset on a person by person basis. These explanatory variables serve as controls for alternative explanations of our findings. They also help to assess the mechanism through which interpersonal effects influence automobile consumption. The Finnish tax return dataset records variables as of three end-of-years 1998 through 2000 inclusive. At the end of each of these three calendar years, we collected the following variables for each tax subject in the two provinces: income, year of birth, sex, marital status (single, married, or unmarried but cohabiting), number of dependents under 18 years old, work-related travel costs, whether the community lived in is city, suburban, or rural, ${ }^{6}$ employment status, existence of residential real estate ownership, and address.

The data are on every resident in the two provinces, both the car owners in the June 10, 2002 FVA dataset, as well as residents who do not own cars on that date. Except for address, the 1998 data are assumed to represent the data for the subjects in 1999; the 1999 data portray these variables for 2000 , etc.

The tax data report move-in and move-out dates for each subject at a given address in a given year. Therefore, addresses for each subject are current for any given day. These addresses were converted to latitude and longitude coordinates on all subjects. The

\footnotetext{
${ }^{6}$ The classification by zip code is provided by Statistics Finland.
} 
coordinates were then translated and rotated with parameters that were destroyed to maintain the anonymity of the subjects in the datasets while preserving their relative distance from one another. $^{7}$

This linking of the FVA and tax datasets generates data on all residents in the provinces, both car purchasers, potential car purchasers, and their neighbors over the 8-year period, 1994-2001, with control variables over the 3-year period, 1999-2001.

\subsection{Data Frequency}

We analyze data at the yearly frequency. Because the purchase history of each neighborhood of a subject changes from day to day, it was necessary to develop a methodology that alleviates concerns about the coefficient biases that intra-year seasonalities in car purchases might induce. In each of the three years studied, the actual purchase dates are used to generate a distribution of non-purchase dates. For example, if over the entire year of 1999, there are 20 times more non-purchasers than purchasers of a car, and if there were 200 purchases on July 12, 1999, then we assume that there were 4000 non-purchases on July 12, 1999. Doing this for every date in 1999 generates a probability distribution function of non-purchases over 365 days that is identical to the probability distribution function for purchases. If an individual has not purchased a car in that year, his or her (shadow) nonpurchase date within that year is randomly assigned using this distribution. For the purpose of understanding how the history of purchase behavior in a neighborhood influences purchase decisions, we compare purchases on particular dates to the shadow non-purchase decision.

\footnotetext{
${ }^{7}$ The data vendor for latitude and longitude coordinates assigns exact latitude and longitude for each street intersection. The vendor, who knows the number of buildings on each side of each street, then interpolates the coordinates to obtain latitude and longitude for each building. The interpolation algorithm assumes that each building between two adjacent intersections is of identical size. For example, if the distance between two adjacent intersections is 200 meters and there are 8 buildings between the two intersections on a given side of the street, then each building is assumed to be 25 meters wide. All individuals living in the same building have the same latitude and longitude coordinates.
} 
Since control variables, (except for the history of car purchases within a particular subject's neighborhood), do not vary day-to-day, this approach generates virtually the same relative coefficients as regressions using daily data (which would involve nearly a billion observations), while maintaining computational feasibility. ${ }^{8}$

\subsection{Data Exclusions, Variable Construction, and Methodology}

For each calendar year analyzed, we excluded residents of the two provinces who lack data on address or income or anyone who resided at the same address for only a portion of the calendar year. We also require that all subjects (whether car purchasers or not), be at least 18 years old before the beginning of the year being analyzed.

Our analysis largely consists of logit regressions, with a binary action of a subject in a given year as the dependent variable. This action may be buy vs. not buy a car, buy vs. not buy a new car, buy vs. not buy a used car, or buy vs. not buy a particular make, like a Honda, or a particular model, like a Honda Accord. The right hand side variables describe the history of the actions of neighbors, and attributes of the subject (including attributes of his neighborhood and point in time) whose action is the dependent variable.

Subjects who appear to be spouses of the subject whose action is being analyzed are excluded as neighbors. ${ }^{9}$ With three years of binary decisions as the dependent variable, we end up with 2,520,575 binary decision observations. Each resident appears as three observations except for those who moved in a given year. In this case, they are excluded from the year of the move.

\footnotetext{
${ }^{8}$ We have verified this by running some of our analysis with monthly data.

${ }^{9}$ Spouses are identified using the following criteria: same latitude and longitude coordinates, same move-in and move-out dates, same marital status, same number of children, opposite sex, age difference less than 10 years. This exclusion avoids confounding neighborhood effects with spousal effects. For example, if one of the spouses buys a car, the other is less likely to buy a car, which would erroneously be interpreted as suggesting that a purchase by the very closest neighbor has a negative effect on the purchase behavior of the subject. While some automobiles are jointly owned, each automobile is listed as having only one primary owner.
} 
The subjects' control variables, which can change from year to year, are as follows. Age: The subject's age in years. It is also entered as the square of age to test for nonlinear effects. ${ }^{10}$ Kids: A dummy variable that takes on the value one if the subject has at least one dependent that is less than 18 years old. ${ }^{11}$ Cohabits: A dummy variable that takes on the value one if the subject individual has a live-in partner he or she is not married to. Rural and suburban dummies: The type of community of the individual analyzed. The zero value for both dummies is classified as a "city area." Homeowners: A dummy variable that is one if the subject has real estate or apartment wealth. Unemployed: A dummy variable that takes on the value of one if the subject collected unemployment benefits for at least one day in the prior calendar year. Travel cost: The subject's work-related travel costs (in euros) declared in the prior year's tax filing. Social class dummies: In each year, all subjects are assigned to one of ten equal-sized deciles based on their total income, which is the sum of income from labor and capital. A person's social class can change each year. If all nine dummies are zero, the person is in the highest income decile. Year dummies: The year of the buy vs. not-buy decision. The omitted dummy is 2001.

For each subject, neighbors are rank-ordered in terms of distance. The 500 closest neighbors are assigned a distance ranking from 1-500 with 500 being the most distant neighbor. If several individuals live exactly at the same distance, the rankings for the individuals within the distance category are assigned randomly. ${ }^{12}$

With these variables in mind, we run pooled time-series and cross-sectional logit regressions with each resident assigned to a single date in a given calendar year. If the subject

\footnotetext{
${ }^{10}$ For privacy protection, all persons born prior to 1910 are assumed to have been born in 1909 . There are only a negligible number of automobile owners within this group, for obvious reasons.

${ }^{11}$ Number of children, as a substitute variable, yields virtually identical results.

${ }^{12}$ Population density is likely to influence neighborhood relationships if we use actual distance in lieu of distance ranks. Moreover, the number of people a person is likely to know and befriend is likely to be fairly independent of population density. This argues for distance ranks as the more appropriate distinguishing characteristic of social influence.
} 
is a purchaser, the date $t$ is the actual purchase date in that year; if a non-purchaser for that year, the date $t$ is the shadow purchase date in the calendar year to which the subject is assigned by the algorithm described earlier.

Our model of the prototypical logit regression used in the paper can be described with the functional form:

Binary Decision (date $t$, subject $i)=f($ date $t$ car purchase history of subject $i$ 's neighborhood) $+g$ (other date $t$ attributes of subject $i$ )

Our primary goal is to infer $f()$ by looking at coefficients that tell us about the relevant arguments of $f()$ and the derivatives of $f()$ with respect to each of those arguments.

\subsection{Dimensions to the car buying decision}

In addition to studying factors that drive the decision to buy or not buy an automobile in a given year, we also analyze the decision of which make to buy, which model to buy, and whether to purchase a new car or a used car.

Each make of car, e.g., Honda or Mercedes, is assigned its own code. Models are assigned dummy variables only if they can be identified as separate models and have been for sale as new cars between 1996 and 2001. Models are aggregated at the main type level. For example, Honda Accords and Honda Civics are treated as separate models, but no attempt has been made to separate the LX and EX versions of the two models.

The model year of the car that is purchased is not reported. Hence, we assess whether a car purchase is new or used with a decision algorithm that makes use of the registration history of an automobile. If registration followed the U.S. standard, cars whose sale date corresponded to the first date of registration would be new cars, and the remainder would be 
used cars. However, Finnish law differs: New vehicles sold to consumers sometimes have already been registered by the dealer. In this case, the first registration date is prior to the sale. The FVA also records an event date, which may correspond to the first date a car registered in a foreign country was brought into Finland from the foreign country. All cars with a sale date greater than six months past the earlier of the event date or the first registration date are assumed to be used cars. It is possible that some new cars sat on dealer lots for more than six months and then were sold; however, such anomalous misclassifications are likely to be rare.

For each of the most important make and model classes, we study separate logit regressions that analyze the decision to buy that particular make or model. In some tables, we report the average and median coefficients across each of the make (model) regressions.

\section{Results}

Table 1 presents summary statistics on the data. Panel A presents the number of residents who purchased or did not purchase an automobile, both new and used, in each of the three years of the study. Panel B breaks the purchases down by month of the year. ${ }^{13}$ As can be seen from this panel, car purchases are relatively rare events for which there is a pronounced seasonality. The warmer weather months and the early fall generate more car buying.

${ }^{13}$ The seasonalities (by month and year) in the fraction of new vs. used cars are partly due to a truncation effect. A new car owned on June 10, 2002 tends to have been owned for a longer period of time than a used car. Since the more distant years and early calendar months in our sample tend to be furthest from June 10,2002 , we see the new car fraction largest in the early calendar months and distant years. For the same reason, the trend towards more car purchases over time is a biased representation of what actually took place. Cars bought in 1999 and sold in 2001 appear only as 2001 purchases in our sample. However, cars tend to be held for a fairly long period of time in Finland, so the increased frequency of purchases may partly be due to Finnish economic growth, which peaked in 2000. This truncation does not affect our conclusions about social influence, which are robust when analyzed with monthly data or run separately for each calendar year. 
Panel $\mathrm{C}$ of Table 1 presents car buying propensities based on several control variables. As can be seen from the Panel C, car buying propensities are smaller for those who are unattached to a significant other or who lack children, renters, females, and urban dwellers. The propensities increase in income, which is our proxy for socioeconomic status.

\subsection{Marginal Effects of Control Variables}

The fourth column of numbers in Table 2 presents the coefficients of our main logit regression. The left hand side dummy variable takes on the value 1 if the subject purchases a car in a particular year. Panel A presents results for the control variables in the regression (as described in the last section). The dummy variable coefficients for all income deciles, except the 9th, are negative, and monotonic in the deciles. The lower the income, the lower is the likelihood of purchasing a car, other things equal. Despite the statistical significance, arising from the large sample size of over 2.5 million observations, the marginal effect of income rank on car buying propensity is about the same for the 8th, 9th, and 10th income deciles. Older people also have a larger propensity to purchase a car, but very old people, as indicated by the age-squared coefficient, have less of a propensity to buy a car than middle-aged people. Males, subjects with children, those who are married or cohabiting with an unmarried partner, homeowners, and those with high travel costs also are more likely to purchase cars. Those collecting unemployment benefits are more likely to purchase cars, perhaps because they have lost access to a company car or other transportation provided by their employer. The urban and suburban dummies indicate that subjects with greater distances to travel are more likely to purchase cars.

The first three columns with numbers in Panel A run the logit regressions separately for city, suburban, and rural communities. The control variables have much the same impact 
as they did in the overall logit regression except that the effect of being single (as opposed to married or cohabiting) no longer has a negative effect on car buying propensity in suburban and rural areas. This may have something to do with the impact of public transportation in cities with young professionals who are single and prefer not have a car. No similar transportation alternative may be available in suburban and rural areas.

Finally, the spread of the income coefficients is larger in cities than in suburban areas and it is larger in suburban areas than in rural areas. This is consistent with the argument that a purchase of a car has the least utility attached to it in cities (where public transportation tends to function well) and least luxury attached to it in rural areas (where public transportation is less available).

\subsection{The Influence of Neighbors on the Automobile Purchase Decision}

Figure 1 reports on the impact of neighbor's purchases. In addition to the control variables used in Panel A, each of the four logit regressions contains 135 variables associated with nearness of neighbors and time at which they bought a car. Each variable is the number of cars purchased by neighbors at a certain distance rank interval and within a certain time interval.

Figure 1 graphs these 135 coefficients for each of the four logit regressions in Panel A. If each neighbor car purchase on a given day has the same influence, no matter how distant the neighbor or how far in the past, and influences are linearly additive, then the 135 coefficients would be identical. Obviously, Figure 1 suggests that they are not. The coefficients for the nearest neighbors and the most recent purchases by those neighbors, graphed closest to the origin, are substantially larger than those elsewhere in the graph. There 
is a sharp peak in each of the graphs, corresponding to the nearest neighbor on the same day. ${ }^{14}$ Each of the surfaces in the four graphs decline as the neighbors become more distant and their purchases occur further back in time. Neighbor purchases that take place more than 30 days ago have little influence. In Panel A (all observations), every coefficient associated with purchase behavior more than 30 days in the past is below .05 ; most coefficients are far smaller. Beyond the ten nearest neighbors, there is only modest influence. Only two of the coefficients exceed .05 , and most are far smaller.

\subsection{A Parsimonious Representation of the Neighborhood Effect}

Figure 1 suggests that there is an effect from the broader community that does not decay as distance increases beyond the 10th nearest neighbor or more than 30 days in the past. Although this "outer ring" effect is negligible by comparison, its existence is not surprising in that no matter how good our controls are, there are certain to be omitted variables. For example, we have no data that might indicate if a particular community has excellent or poor public transportation. Cross-sectional variation across communities in this unobservable dimension could generate a spurious neighborhood effect. Viewed another way, the function $g()$ in our model

Binary Decision (date $t$, subject $i)=f($ date $t$ car purchase history of subject $i$ 's neighborhood) $+g$ (other date $t$ attributes of subject $i$ )

depends on both observable and unobservable attributes. Unobservable attributes that are correlated with the neighborhood's car purchase history could bias the coefficients used to infer $f()$. We want to understand how automobile purchase decisions by neighbors arising

\footnotetext{
${ }^{14}$ As suggested earlier, we have been careful about excluding spouses.
} 
from their specific idiosyncratic preferences alter purchase propensities among very near neighbors. To isolate this effect, even in the presence of unobservable control variables, we create the variable

Neighborhood effect: the number of cars purchased by the 10 nearest neighbors in the last 10 days in excess of the expected number of purchases among the ten nearest neighbors,

where the expected number of purchases among the 10 nearest numbers is computed as the $1 / 4$ the number of purchases among the neighbors ranked 11th through 50th in nearness over the prior ten days. The latter can be viewed as a base neighborhood purchase rate. Subtracting it controls for omitted common factors that influence neighborhood purchases. This subtraction effectively orthogonalizes the argument of the function $f()$ to any omitted variable in the function $g\left(\right.$ ) that drives purchases in the larger neighborhood. ${ }^{15} 16$

Panel B of Table 2 describes the logit regression results using this more parsimonious one-variable representation of the neighborhood effect in lieu of the more complex 135 neighborhood variables. The control variables have approximately the same coefficients as those in Panel A. The coefficient on neighborhood effect, .112, is highly significant with a $t$ statistic of 9.71. In other words, the logged odds ratio increases by .112 if your 10 nearest neighbors recently purchased one additional car relative to your more distant neighbors in the

15 The neighborhood effect measured by this variable is a conservative estimate of the true neighborhood effect. This is because not all of the neighborhood effect is confined to the ten closest neighbors. In addition to controlling for unobservable factors, this variable also deducts some genuine neighborhood effect by subtracting the influence of the "outer ring" neighbors.

${ }^{16}$ Our results are qualitatively similar when we use thirty days as the window for past purchases by neighbors in lieu of ten days, although a bit weaker. This is partly attributable to noise in the influence variable. When we lengthen the window, the comparison group, (the outer ring), is more likely to generate purchases. Given the fact that these outer ring consumers are considerably less influenced by the neighborhood effect, cumulating their purchases over a longer horizon generates more noise in the variable. 
same time frame. Because the odds ratio is close to zero (as the probability of buying a car is small), a logit coefficient of .112 means that the probability of a car purchase is scaled up by a factor of about 12 per cent (multiplied by about 1.12) for each additional near neighbor purchase in the last ten days. Given that the daily probability of buying a car is close to zero, one still achieves a negligible probability of a car purchase on a given day no matter how many neighbors have purchased cars in the last ten days. However, as a percentage of that low probability of a car purchase on a given day, the increase is quite substantial. ${ }^{17}$

\subsection{How Population Density and Social Class Modify the Influence of Neighbors}

Panel B of Table 2 indicates that neighborhood influence varies inversely with population density: Rural areas exhibit the greatest neighborhood influence while cities exhibit the least. Figure 1 elaborates on this in showing that the neighborhood influence differences across the first 3 columns of Table 2 Panel B are largely driven by the influence of the nearest neighbor purchasing a car 0-4 days prior to the date of the car buying decision. On day 0 , for example, the coefficient on the same day, the nearest neighbor dummy coefficient is more than twice as large for rural areas as it is for cities. This pattern is inconsistent with a prediction of Veblen (1899/1931, pp. 88-89). He pointed out that residents of rural areas are more familiar with each other and thus would be less apt to emulate conspicuous consumption. ${ }^{18}$ There is no point to signaling status via consumption when your neighbors already know that status. However, despite the additional distance, the stronger ties to

17 The summary statistics here are also impressive. Of the 211,173 purchases, there were 7,662 purchases by the 10 nearest neighbors in the prior ten days, which is 1,983 more purchases than would be expected by chance.

${ }^{18} \mathrm{He}$ also mentioned that rural areas are less prone to conspicuous consumption because they maintain a lower standard of decency. 
neighbors in less densely populated areas generate more social influence on consumption, not less. $^{19}$

Figure 2 plots the neighbor influence coefficient for the regression in Panel B run separately for each income decile. Those in the lowest social classes are most influenced by neighbor purchases. This is a rather surprising finding if emotion or envy is the source of emulation. First, there is no a priori reason to think that those in the lowest income are the most susceptible to emotional urges in their consumption of luxury goods. Indeed, behavioral theories of consumption (e.g., Duesenberry (1949/1962, last paragraph) suggest that social considerations are most important in the upper income groups. Moreover, the loss to intrinsic well being from a consumption "mistake" due to envy is far greater for someone with less income. Under fully rational consumption, the basket of goods of a lower income consumer has a larger proportion of necessities. For this consumer, indulgence in luxury goods due to envy or urge to conform is more likely to crowd out necessities like shelter or food. If a consumption "mistake," like a Mercedes-Benz purchase arising only from envy of a neighbor is a greater sacrifice for those in the lowest income classes, it is less likely to happen. The data do not support this prediction.

An explanation that accounts for the presence of consumption emulation within the lowest income groups is information sharing. Uncertainty about quality and final pricing is a larger problem with used and/or inexpensive automobiles. Thus, consumers in the lower income classes would tend to observe the actions of others and communicate with others to resolve this uncertainty. We will test this hypothesis shortly by analyzing the used vs. new car social influence coefficient.

\footnotetext{
${ }^{19}$ There is another explanation that accounts for some but not all of this result. In urban settings, many buildings contain more than ten residents. In these cases, we cannot pinpoint the ten nearest neighbors. (In cases where we can, the urban and rural influence coefficients are far closer, but the rural coefficient is still larger.)
} 
Figure 3, which plots the same coefficient for regressions run separately by the differences in income deciles, indicates that the emulation of neighbors in higher income deciles does not entirely drive the purchases. Neighbors in one's own income decile have about the same influence coefficient as neighbors in higher income deciles. On the other hand, the influence of neighbors in the three higher income deciles is about twice as large as the influence in the three lower deciles. While this is consistent with Veblen's conspicuous consumption hypothesis and Duesenberry's relative income hypothesis, neither would have predicted that there would be any influence from those in a lower income decile. ${ }^{20}$

Table 3 quantifies these phenomena in more detail. The first column of coefficients, used for comparison purposes, is the regression from Table 2 Panel B. The second and third columns focus on the influence of neighbors who fall into the higher, same, or lower income deciles. The second and third columns show that the car purchase behavior of neighbors in the same income decile has the greatest influence, while the least influence is among neighbors in lower income deciles. (The fourth column, Model 4, was reported on in Figure 2.)

On balance, we attribute the pattern of influence among neighbors as a phenomenon that is related to information dissemination. An additional piece of evidence for this is that purchases by very near neighbors on the same day or in the very recent past drive the neighbor influence phenomenon. It is plausible that neighbors exchange information about the attributes of automobiles or dealer pricing and this information sharing induces similar purchases among neighbors. For the same day purchases, it is likely that neighbors who have

\footnotetext{
${ }^{20}$ Veblen (1931, Chapter 5) writes, “... each class envies and emulates the class next above it in the social scale, while it rarely compares itself with those below or with those who are considerably in advance. Duesenberry (1962, p. 101) states "Low-income groups are affected by the consumption of high-income groups but not vice versa. ... The lowest-income group will be affected by the consumption of the next higher group but not vice versa, the lowest but one will be affected by the next higher but not vice versa, and so on." On the other hand, income is a noisy proxy for social status. Variables affecting social status that we do not control for, like education, could account for some of the modest influence of lower income deciles.
} 
shared information are shopping together. It is unlikely that a purchase is taking place in the afternoon to keep up with a neighbor's purchase in the morning. Envy is a more persistent emotion. The Mercedes in your neighbor's driveway does not go away after a few days, a few months, or even a few years. If envy of it were driving you to consume, there is no reason to believe that influence would decline so rapidly as time elapsed since the neighbor's purchase.

If the information story is behind the neighbor influence coefficient pattern, the value of the neighbor's information from the purchase (or pre-purchase research) should decline with time. For one, new models of the neighbor's car and substitutes for it are being introduced all the time. Public information about these automobiles, via consumer and government testing units also may dilute the value of the neighbor's information over time. The neighbor's information also may have been disseminated prior to purchase, perhaps months earlier. If it is a new car, the vehicle order may have been placed long before the recorded purchase date.

This information could be about the quality of the car, but given the rapidity of the decline in the social influence coefficient over time, it is just as likely, if not more likely, to be information about pricing. For example, a consumer may travel to the dealer, find that the dealer is more flexible about pricing or financing than expected. He might also discover that the dealer has a large inventory to dispose of or an inventory containing exactly the same hard-to-get color that the neighbor is looking for. Communicating this relatively private information to close friends leads to an abnormal number of purchases within a concentrated social circle.

It is also possible that the purchase of a car triggers a sale of the purchaser's previously owned car to a neighbor or vice versa. However, the ages of cars purchased by 
nearby neighbors (ranked 1-10) in the last 30 days, are significantly closer to one another ( $t$ value $=3.04)$ than the ages of cars purchased by more distant neighbors (ranked 11-50). ${ }^{21}$ This is the opposite of what an abundance of neighbor-to-neighbor sales would predict. Moreover, if intra-neighborhood sales were the explanation for the social influence coefficient, one would predict that close neighbors would not exhibit any additional concentration of purchases of individual makes and models. We investigate this issue next.

\subsection{Purchases of Used vs. New Cars and of Particular Makes and Models}

If information drives the influence coefficient, we would not expect the influence to be about automobiles in general. Learning that financing rates for all automobiles are low might be important, but it is less likely to be a critical piece of information among closest neighbors than information about a specific make or model's qualities or pricing. Learning that a particular make of car accelerates very nicely, that the seats are comfortable, or that research done by the neighbor suggests it gets great fuel mileage or doesn't tend to require frequent repairs, is more likely to be useful to a prospective consumer. Similarly, it is more useful to learn that a particular dealer who specializes in Volvo wagons is likely to give favorable financing terms because of his current inventory situation. Such information may not be as readily available from public sources. Even if it is information of a type that is advertised in the classified section of a newspaper, friends may further publicize the information by calling attention to it with a purchase or by announcing it in conversation.

Thus, the information story predicts that we would also expect similar makes and models to be purchased by neighbors. We might also expect neighbor influence to be more of a used car purchase phenomenon, where quality concerns or pricing ambiguity may be more

\footnotetext{
${ }^{21}$ The same finding applies if we restrict our focus to purchases in the last ten days.
} 
important. Behavioral models of social influence on consumption would almost certainly argue that new car purchases by neighbors would have a greater influence on purchase behavior.

The first coefficient column in Table 4 indicates that a neighbor's used car purchase affects the probability of a purchase more than a new car purchase. The used car coefficient is about $50 \%$ larger than the new car coefficient. As discussed above, this is not consistent with behavioral theories of social influence on consumption, but it may be indicative of information sharing among neighbors.

To investigate this further, Table 4 analyzes new car purchases and used car purchases separately. In the second column, the dependent (dummy) variable is one only if the subject makes a new car purchase. In the third column, it is one only if the subject makes a used car purchase. Clearly, used car purchases by neighbors influence used car purchases to a greater extent than new car purchases by neighbors influence used car purchases. Similarly, new car purchases by neighbors influence new car purchases more than new car purchases influence used car purchases. The larger new car to new car and used car to used car coefficients are consistent with information being disseminated about like automobiles. On the other hand, it may also be consistent with keeping up with (but not one-upping) the Joneses.

The table documents that used car purchases are partly influenced by neighbors' purchases of new cars. One can debate whether behavioral theories predict this. On the one hand, is it possible to "keep up with the Joneses" when they buy a new car by buying a used car? On the other hand, one might argue that lower income consumers lack the means to perfectly emulate the upper classes, but that doesn't mean their attempts at imitation reflect a weaker emotional urge. People do buy fake Rolex watches for a reason. In the end, however, the behavioral theories force us to accept too many anomalies, even within this table, to be 
credible. For example, if the Joneses buy a used car, behavioral theories, like Veblen's conspicuous consumption, should also predict that we might observe some consumers "oneupping" the Joneses by buying a new car. Yet that does not happen.

Consistent with the information hypothesis, the influence of neighbors' used car purchases on used car purchases is clearly greater than the influence of neighbors' new car purchases on new car purchases. Advertising, reviews, and warrantees all serve to mitigate the asymmetric information problem in new car purchases, or serve as an additional set of factors that influence purchases. They operate to a lesser degree in the used car market if at all.

To help further resolve the issue of whether information or behavioral considerations drive these results, Table 5 Panel A analyzes the logit regression of Tables 2 and 3 separately for each of the 15 most popular makes of automobiles. Panel A focuses on two influence variables rather than one. "Same make" is the number of purchases of the make listed in the row among the 10 nearest neighbors within the last 10 days (adjusted for the expected number of purchases of that make, in a manner analogous to the adjustment employed for the influence variable used previously in the paper). The "other makes" variable is the number of purchases of a make other than that listed in the row among 10 nearest neighbors within the last 10 days (adjusted for the expected number of purchases of the other makes). Clearly, a purchase by a neighbor tends to generate a purchase of the same make. The average coefficient for "same make" is more than five times the size of the influence coefficient for "other makes." For about half the makes, there is no significant influence on the purchase probability arising from a neighbor's purchase of a different make.

The difference is even stronger for the average coefficient of the same model when we look at the 10 most popular models. The variables for same make and model and same make 
different model are computed analogously to the influence variables studied in Panel A. As Table 5 Panel B reports, the median "same make and model" influence coefficients are almost twice as large as the "same make different model" influence coefficients and almost 10 times larger than the "other make" influence coefficient. Indeed, as Panel B indicates, only 3 of the 10 most popular models are significantly influenced by neighbors' purchases of different makes.

Shared information about particular makes and models appears to be driving the shared desire among neighbors to purchase a car. On the other hand, almost all of the coefficients on the different make or model neighbor influence variable are positive. It is therefore possible that at least a small portion of a neighbor's influence is not due to information but to envy.

\section{Conclusion}

This study has documented a highly significant social influence in Finnish automobile consumption. One's nearest neighbors' purchases appear to influence purchases, particularly of the same make and model, and of used cars, and to a far larger extent within a short time frame. It is difficult to argue that emotional biases lie behind the social influence observed when the social influence on consumption is intensified to such a degree by these factors. That does not have to mean that behavioral effects, rooted in psychological biases, will never be found in consumption. However, we looked hard and have superb data to help identify behavioral effects that might drive the social influence. Frankly, the evidence supporting emotion as a key driver of the social influence on consumption is not there.

Since common folk wisdom suggests that consumption of this commodity is particularly prone to interpersonal behavioral influences like envy or snobbery, the absence of 
behaviorally generated social influences in this consumption arena calls into question the efficacy of such models in other economic applications where the data are not of the same quality.

Information transmission of some sort is better at explaining why consumers are observed to keep up with the Joneses. We consider this a rather promising finding. Information asymmetries and whether and how they are resolved have always been critical to economics. However, it is only in the last 30 years that the field has witnessed an explosion in the theoretical study of these important topics. There are now a variety tools and insights that allow researchers to more accurately model the role that information plays in the consumption function. Particularly with capital goods, like automobiles, where consumption decisions that are costly to reverse become long-term, information is essential. While the formation of preferences and its link to information and learning has not been on the short list of hot topics in economics, we contend that it offers a rich array of theoretical opportunities as well as an exciting challenge for empirical researchers. The fact that the neighbors exerting influence are particularly close suggest that there may be geographic barriers to learning that are worth investigating.

There is very little evidence that neighborhood effects are tied to anything but geographic information barriers. One should not interpret this finding as suggesting that behavioral economics has no role to play in understanding issues like equilibrium, just that behavioral factors may be of far smaller import than information barriers. 


\section{REFERENCES}

Abel, Andrew B. "Asset Prices under Habit Formation and Catching up with the Joneses." American Economic Review, May 1990, 80(2), pp. 38-42.

Akerlof, George. "Social Distance and Social Decision." Econometrica, September 1997, 65(5), pp. 1005-1027.

Bagwell, Laurie Simon and Bernheim, B. Douglas. "Veblen Effects in a Theory of Conspicuous Consumption.” American Economic Review, June 1996, 86(3), pp. 349-373.

Basmann, Robert L; Molina, David J. and Slottje, Daniel J. "A Note on Measuring Veblen's Theory of Conspicuous Consumption." Review of Economics and Statistics, August 1988, 70(3), pp. 531-535.

Bearden, William and Etzel, Michael J. "Reference Group Influence on Product and Brand Purchase Decisions.” Journal of Consumer Research, September 1982, 9(2), pp. 183194.

Becker, Gary S. "A Theory of Social Interactions." Journal of Political Economy, November-December 1974, 82(6), pp. 1063-1093.

Bernheim, B. Douglas. "A Theory of Conformity." Journal of Political Economy, October 1994, 102(5), pp. 841-877.

Bikhchandani, Sushil; Hirshleifer, David and Welch, Ivo. "A Theory of Fads, Fashion, Custom, and Cultural Changes as Informational Cascades." Journal of Political Economy, October 1992, 100(5), pp. 992-1026.

Bourne, Francis S. "Group Influence in Marketing and Public Relations," in Some Applications of Behavioral Research, eds., R. Likert and S.P. Hayes. 1957, Basil, Switzerland: UNESCO.

Campbell, John and Cochrane, John, "By Force of Habit: A Consumption-Based Explanation of Aggregate Stock Market Behavior.” Journal of Political Economy, April 1999, 107(2), pp. 205-251.

Chan, Yeung Lewis and Kogan, Leonid. "Catching up with the Joneses: Heterogeneous Preferences and the Dynamics of Asset Prices." Journal of Political Economy, December 2002, 110(6), pp. 1255-1285.

Deutsch, Morton and Gerard, Harold B. "A Study of Normative and Informational and Social Influences upon Individual Judgment." Journal of Abnormal and Social Psychology, 1955, 51, pp. 624-636. 
Duesenberry, James S. "Income, Saving, and the Theory of Consumer Behavior." Harvard University Press, Cambridge, Massachusetts, 1962, fourth printing (originally published 1949).

Fishman, Arthur. "Search Technology, Staggered Price-Setting, and Price Dispersion." American Economic Review, 1992, 82(1), pp. 287-298.

Friedman, Milton, A Theory of the Consumption Function, Princeton, New Jersey, 1957, Princeton University Press.

Gali, Jordi. "Keeping Up with the Joneses: Consumption Externalities, Portfolio Choice, and Asset Prices." Journal of Money, Credit and Banking, February 1994, 26(1), pp. $1-8$.

Leibenstein, Harvey. "Bandwagon, Snob, and Veblen Effects in the Theory of Consumers' Demand." Quarterly Journal of Economics, May 1950, 64(2), pp. 183-207. Company.

Marshall, Alfred, Principles of Economics, 1890, New York, MacMillan and

Morgenstern, Oskar, "Demand Theory Reconsidered." Quarterly Journal of Economics, February 1948, 62(2), pp. 165-201.

Pesendorfer, Wolfgang. "Design Innovation and Fashion Cycles." American Economic Review, September 1995, 85(4), pp. 771-792.

Peter, J. Paul and Olson, Jerry C. "Consumer Behavior and Marketing Strategy." McGraw-Hill Irwin, 2001, sixth edition.

Pollack, Robert A. "Independent Preferences." American Economic Review, June 1976, 66(3), pp. 309-320.

Robson, Arthur J. "Status, the Distribution of Wealth, Private and Social Attitudes to Risk." Econometrica, July 1992, 60(4), pp. 837-857.

Solomon, Michael R. "Consumer Behavior. Buying, Having, and Being." Prentice Hall, New Jersey, 1999, fourth edition.

Stigler, George. "The Development of Utility Theory. II." Journal of Political Economy, October 1950, 58(5), pp. 373-396.

Veblen, Thorstein, "The Theory of the Leisure Class. An Economic Study of Institutions." 1899 (original publication date), Random House, 1931, tenth printing.

Veblen, Thorstein, "Why is Economics Not an Evolutionary Science?" Quarterly Journal of Economics, July 1898, 12, pp. 373-397. 
Table 1

Descriptive statistics of automobile purchases and non-purchases

For each of the three years 1999 to 2001, Panel A reports the total number of car purchases and non-purchases in two Finnish provinces. Automobile purchases are classified into two main categories, new cars and used cars. A car is assumed new if its sale occurs no more than six months after the first registration day. Individuals who did not purchase a car in a given year are recorded as non-purchasers. Panel B reports the monthly distribution of purchases and non-purchases. In a given year, the number of non-purchases for a particular month has been computed by assuming that the distribution of non-purchase dates is the same as the distribution of purchase dates. The fraction of new automobile purchases indicates the proportion of new car purchases to all purchases. Panel $\mathrm{C}$ reports the propensity to purchase in each of the three years based on classifications using the following control variables: gender, age, marital status (single, cohabits or married), dependents under 18 years (yes/no), total income rank deciles (based on labor plus capital income), homeownership status, employment status, and the type of community in which the subject is living (urban, suburban, or rural).

Panel A. Number of purchases and non-purchases by year

\begin{tabular}{lcccc}
\hline & 1999 & 2000 & 2001 & Totals \\
\hline New car purchases & 19,922 & 24,066 & 19,993 & 63,981 \\
Used car purchases & 34,100 & 49,367 & 63,725 & 147,192 \\
Purchases, totals & 54,022 & 73,433 & 83,718 & 211,173 \\
Non-purchases & 774,467 & 773,942 & 760,993 & $2,309,402$ \\
Purchases and non-purchases, totals & 828,489 & 847,375 & 844,711 & $2,520,575$ \\
\hline
\end{tabular}

Panel B. Number of purchases and non-purchases by month

\begin{tabular}{lcccc}
\hline Month & Purchases & Non-purchases & Totals & Fraction of new \\
\hline 1 & 15,280 & 168,861 & 184,141 & 0.394 \\
2 & 13,696 & 150,493 & 164,189 & 0.333 \\
3 & 17,363 & 191,357 & 208,720 & 0.329 \\
4 & 17,816 & 197,846 & 215,662 & 0.334 \\
5 & 20,402 & 223,330 & 243,732 & 0.337 \\
6 & 18,999 & 208,854 & 227,853 & 0.316 \\
7 & 18,984 & 208,076 & 227,060 & 0.280 \\
8 & 19,752 & 213,846 & 233,598 & 0.281 \\
9 & 19,052 & 208,150 & 227,202 & 0.279 \\
10 & 19,541 & 210,715 & 230,256 & 0.270 \\
11 & 17,098 & 184,738 & 201,836 & 0.257 \\
12 & 13,190 & 143,136 & 156,326 & 0.227 \\
Totals & 211,173 & $2,309,402$ & $2,520,575$ & 0.303 \\
\hline
\end{tabular}


Panel C. Propensity to purchase by year

\begin{tabular}{|c|c|c|c|c|}
\hline & \multicolumn{4}{|c|}{ Propensity to purchase by year } \\
\hline & 1999 & 2000 & 2001 & Totals \\
\hline Females & 0.038 & 0.051 & 0.056 & 0.048 \\
\hline Males & 0.096 & 0.128 & 0.148 & 0.124 \\
\hline $18-24$ & 0.036 & 0.059 & 0.085 & 0.060 \\
\hline $25-29$ & 0.064 & 0.095 & 0.128 & 0.096 \\
\hline $30-34$ & 0.078 & 0.109 & 0.136 & 0.107 \\
\hline $35-39$ & 0.084 & 0.111 & 0.132 & 0.109 \\
\hline $40-44$ & 0.084 & 0.109 & 0.128 & 0.107 \\
\hline $45-49$ & 0.082 & 0.106 & 0.119 & 0.102 \\
\hline $50-54$ & 0.080 & 0.104 & 0.111 & 0.098 \\
\hline $55-59$ & 0.075 & 0.095 & 0.100 & 0.091 \\
\hline $60-64$ & 0.062 & 0.077 & 0.078 & 0.073 \\
\hline $65-69$ & 0.049 & 0.058 & 0.058 & 0.055 \\
\hline $70-$ & 0.021 & 0.025 & 0.025 & 0.024 \\
\hline Single & 0.048 & 0.068 & 0.083 & 0.067 \\
\hline Cohabits & 0.086 & 0.120 & 0.147 & 0.118 \\
\hline Married & 0.081 & 0.104 & 0.113 & 0.099 \\
\hline No kids & 0.055 & 0.074 & 0.086 & 0.072 \\
\hline Kids & 0.090 & 0.119 & 0.136 & 0.115 \\
\hline Lowest income & 0.026 & 0.036 & 0.046 & 0.036 \\
\hline 2 & 0.029 & 0.046 & 0.061 & 0.046 \\
\hline 3 & 0.028 & 0.043 & 0.056 & 0.042 \\
\hline 4 & 0.033 & 0.046 & 0.058 & 0.046 \\
\hline 5 & 0.050 & 0.066 & 0.080 & 0.066 \\
\hline 6 & 0.060 & 0.081 & 0.098 & 0.080 \\
\hline 7 & 0.071 & 0.098 & 0.114 & 0.095 \\
\hline 8 & 0.091 & 0.119 & 0.135 & 0.115 \\
\hline 9 & 0.109 & 0.139 & 0.149 & 0.132 \\
\hline Highest income & 0.120 & 0.149 & 0.151 & 0.140 \\
\hline Non-homeowner & 0.045 & 0.066 & 0.087 & 0.066 \\
\hline Homeowner & 0.081 & 0.103 & 0.108 & 0.098 \\
\hline Employed & 0.065 & 0.089 & 0.100 & 0.084 \\
\hline Unemployed & 0.065 & 0.070 & 0.094 & 0.081 \\
\hline Urban & 0.055 & 0.073 & 0.083 & 0.070 \\
\hline Suburban & 0.081 & 0.106 & 0.119 & 0.102 \\
\hline Rural & 0.090 & 0.122 & 0.144 & 0.119 \\
\hline Whole sample & 0.065 & 0.087 & 0.099 & 0.084 \\
\hline
\end{tabular}


Table 2

Baseline logit regressions of neighbor influence by type of community

Table 2 reports coefficients and test statistics for subsets of variables for eight logit regressions. The dependent variable in all regressions is a dummy variable indicating whether an individual purchased a car in a given year. Panel A reports the coefficients of control variables and their $t$-values for three types of communities: cities, suburban, and rural areas, as well as for the overall regression. The control variables include male dummy, the subject's age in years, the square of age, a dummy variable that is 1 if the subject has at least one dependent, marital status dummy $(1=$ married $)$, a cohabit dummy $(1=$ have a live in partner $)$, rural and suburban dummies depending on the type of community in which the subject lived, homeownership dummy (if the subject had real estate or apartment wealth the previous year), unemployment dummy (if the subject collected unemployment benefits during the prior year), travel costs (the subject's work-related travel costs in euros during the prior year), social class decile rank dummies, based on the sum of labor and capital income, and year dummies for years 1999 and 2000. The 135 time-distance variables included in the regression are reported in Figure 1. Each time-distance variable is computed as the number of cars purchased by the neighbors at that distance rank and time interval. Panel B reports results from parsimonious neighborhood effect regressions analogous to those in Panel A. Instead of the battery of 135 time-distance variables in Panel A, the neighbor effect is the number of automobiles purchased by the 10 nearest neighbors in the last 10 days less one quarter the number of purchases by the neighbors ranked $11^{\text {th }}$ through $50^{\text {th }}$ in nearness in the last ten days. This parsimonious regression specification includes the same control variables as Panel A, but the coefficients on the control variables are omitted for brevity. 
Panel A. Control variables for 135 time-distance variable regressions

\begin{tabular}{|c|c|c|c|c|c|c|c|c|}
\hline \multirow[b]{2}{*}{ Independent variables } & \multicolumn{4}{|c|}{ Coefficients } & \multicolumn{4}{|c|}{$t$-values } \\
\hline & \multicolumn{2}{|c|}{ City Suburban } & \multirow{2}{*}{$\begin{array}{r}\text { Rural } \\
-2.857\end{array}$} & \multirow{2}{*}{$\begin{array}{r}\text { All } \\
-3.468\end{array}$} & \multicolumn{2}{|c|}{ City Suburban } & \multirow{2}{*}{$\begin{array}{r}\text { Rural } \\
-38.94\end{array}$} & \multirow{2}{*}{$\begin{array}{r}\text { All } \\
-124.90\end{array}$} \\
\hline (Constant) & -3.560 & -3.342 & & & -98.33 & -54.13 & & \\
\hline Male & 0.977 & 0.836 & 0.668 & 0.884 & 139.40 & 82.26 & 55.72 & 170.63 \\
\hline Age & 0.028 & 0.033 & 0.030 & 0.029 & 20.27 & 14.88 & 11.45 & 26.94 \\
\hline Age squared & -0.001 & -0.001 & -0.001 & -0.001 & -34.59 & -22.65 & -19.49 & -45.14 \\
\hline Kids & 0.026 & 0.017 & 0.042 & 0.022 & 2.94 & 1.37 & 2.86 & 3.41 \\
\hline Married & 0.146 & -0.015 & -0.057 & 0.084 & 17.63 & -1.14 & -3.74 & 13.30 \\
\hline Cohabits & 0.162 & 0.018 & -0.038 & 0.109 & 9.40 & 0.75 & -1.37 & 8.75 \\
\hline Rural & & & & 0.203 & & & & 25.09 \\
\hline Suburban & & & & 0.096 & & & & 15.00 \\
\hline Homeowner & 0.176 & 0.180 & 0.147 & 0.168 & 22.72 & 14.70 & 10.39 & 28.36 \\
\hline Unemployed & 0.128 & 0.089 & 0.118 & 0.119 & 9.27 & 4.15 & 4.87 & 11.40 \\
\hline Travel cost & $2.0 \mathrm{E}-06$ & $1.5 \mathrm{E}-05$ & $1.2 \mathrm{E}-05$ & $8.3 \mathrm{E}-06$ & 2.46 & 18.76 & 15.36 & 18.21 \\
\hline \multicolumn{9}{|l|}{ Individual's social class } \\
\hline Lowest & -1.347 & -1.147 & -0.990 & -1.227 & -57.64 & -33.91 & -24.69 & -71.30 \\
\hline 2 & -1.019 & -0.763 & -0.642 & -0.887 & -57.37 & -28.56 & -20.24 & -66.69 \\
\hline 3 & -0.824 & -0.565 & -0.471 & -0.703 & -48.58 & -22.05 & -15.86 & -55.57 \\
\hline 4 & -0.700 & -0.412 & -0.295 & -0.564 & -43.89 & -17.47 & -10.51 & -47.52 \\
\hline 5 & -0.428 & -0.206 & -0.141 & -0.327 & -30.80 & -10.18 & -5.59 & -31.52 \\
\hline 6 & -0.285 & -0.106 & -0.077 & -0.205 & -22.22 & -5.71 & -3.27 & -21.47 \\
\hline 7 & -0.183 & -0.056 & 0.006 & -0.121 & -15.27 & -3.25 & 0.27 & -13.52 \\
\hline 8 & -0.054 & 0.030 & 0.081 & -0.014 & -4.81 & 1.89 & 3.78 & -1.65 \\
\hline 9 & 0.017 & 0.068 & 0.105 & 0.040 & 1.61 & 4.53 & 4.97 & 4.95 \\
\hline Year 1999 & -0.144 & -0.157 & -0.208 & -0.138 & -12.78 & -7.27 & -7.65 & -14.84 \\
\hline Year 2000 & -0.020 & -0.025 & -0.039 & -0.015 & -2.21 & -1.64 & -2.04 & -2.13 \\
\hline Cox \& Snell R Square & 0.042 & 0.042 & 0.048 & 0.046 & & & & \\
\hline Nagelkerke R Square & 0.104 & 0.087 & 0.092 & 0.104 & & & & \\
\hline $\mathrm{N}$ & $1,636,620$ & 552,648 & 331,307 & $2,520,575$ & & & & \\
\hline
\end{tabular}

Panel B: Parsimonious regressions

\begin{tabular}{lrrrr}
\hline & City & Suburban & Rural & All \\
\hline Neighborhood effect & 0.058 & 0.135 & 0.176 & 0.112 \\
$t$-value & 3.31 & 6.53 & 7.67 & 9.71 \\
& & & & \\
Cox \& Snell R Square & 0.04 & 0.041 & 0.046 & 0.044 \\
Nagelkerke R Square & 0.099 & 0.084 & 0.088 & 0.101 \\
$\mathrm{~N}$ & $1,636,620$ & 552,648 & 331,307 & $2,520,575$ \\
\hline
\end{tabular}


Table 3

Effects of social class as moderators of neighbor influence

Table 3 reports coefficients and $t$-statistics (below the coefficient) for four logit regressions. The dependent variable in all regressions is a dummy variable indicating whether an individual purchased a car in a given year or not. In Model 1, the neighbor effect is the number of automobiles purchased by the 10 nearest neighbors in the last 10 days less onequarter the number of purchases among the neighbors ranked $11^{\text {th }}$ through $50^{\text {th }}$ in nearness in the last ten days. In Models 2 thru 4, neighbor purchases are computed in an analogous manner, but are divided into two or more subcategories depending on the social class of the neighbors in relation to that of the subject. The social class of a subject and her neighbor are based on their total income (labor plus capital income). Social class 1 refers to the lowest total income decile of all individuals in the sample and social class 10 to the highest total income decile. The control variables are the same as in Table 2, but their coefficients are omitted for brevity.

\begin{tabular}{|c|c|c|c|c|}
\hline Independent variables & Model 1 & Model 2 & Model 3 & Model 4 \\
\hline \multicolumn{5}{|l|}{ Neighborhood effect conditional on } \\
\hline \multirow[t]{2}{*}{ All observations } & 0.112 & & & \\
\hline & 9.71 & & & \\
\hline \multirow[t]{2}{*}{ Neighbor's social class lower than individual's social class } & & 0.083 & 0.083 & \\
\hline & & 4.55 & 4.55 & \\
\hline \multirow[t]{2}{*}{ Neighbor's social class the same as individual's social class } & & 0.146 & & \\
\hline & & 5.07 & & \\
\hline \multirow[t]{2}{*}{ Neighbor's social class greater than individual's social class } & & 0.115 & & \\
\hline & & 6.54 & & \\
\hline \multirow[t]{2}{*}{ Neighbor's social class greater than or equal to individual's social class } & & & 0.123 & \\
\hline & & & 8.22 & \\
\hline \multicolumn{5}{|l|}{ Neighbor's social class - Individual's social class equals } \\
\hline \multirow[t]{2}{*}{-3} & & & & 0.103 \\
\hline & & & & 2.27 \\
\hline \multirow[t]{2}{*}{-2} & & & & 0.050 \\
\hline & & & & 1.27 \\
\hline \multirow[t]{2}{*}{-1} & & & & 0.009 \\
\hline & & & & 0.25 \\
\hline \multirow[t]{2}{*}{0} & & & & 0.146 \\
\hline & & & & 5.07 \\
\hline \multirow[t]{2}{*}{1} & & & & 0.087 \\
\hline & & & & 2.58 \\
\hline \multirow[t]{2}{*}{2} & & & & 0.136 \\
\hline & & & & 3.58 \\
\hline \multirow[t]{2}{*}{3} & & & & 0.108 \\
\hline & & & & 2.49 \\
\hline \multirow[t]{2}{*}{ Other } & & & & 0.140 \\
\hline & & & & 6.57 \\
\hline
\end{tabular}


Table 4

Used vs. New Cars: Neighbor Influence Regressions

Table 4 reports coefficients and $t$-statistics (below the coefficient) for three logit regressions. In the first column, the dependent variable is a dummy variable indicating whether an individual purchased any car in a given year. In the second column, the dependent variable is a dummy variable indicating whether an individual purchased a new car in a given year. A car is assumed new if its sale occurs no more than six months after the first registration day. In the third column, the dependent variable is a dummy variable indicating whether an individual purchased a used car in a given year. The new (used) car neighbor effect is the number of new (used) automobiles purchased by the 10 nearest neighbors in the last 10 days less one quarter the number of new (used) car purchases among the neighbors ranked $11^{\text {th }}$ through $50^{\text {th }}$ in nearness in the last ten days. The control variables are the same as in Table 2, but their coefficients are omitted for brevity.

\begin{tabular}{lccc}
\hline & Buy any car & Buy new car & Buy used car \\
Neighborhood effect conditional on & vs. not & vs. not & vs. not \\
\hline Neighbor bought new car & 0.082 & 0.084 & 0.072 \\
& 3.80 & 2.33 & 2.83 \\
Neighbor bought used car & 0.124 & 0.012 & 0.159 \\
& 9.10 & 0.48 & 10.20 \\
\hline
\end{tabular}


Table 5

Effects of the similarity of make and model on neighbor influence

Panel A reports coefficients and $t$-statistics for fifteen logit regressions. The dependent variable is a dummy variable indicating whether an individual purchased a car representing the given make in a given year. The same make (other makes) neighbor variable is the number of automobiles representing the same (a different) make purchased by the 10 nearest neighbors in the last 10 days less one quarter the number of same (different) make purchases among the neighbors ranked $11^{\text {th }}$ through $50^{\text {th }}$ in nearness in the last ten days. Panel B shows the results for 10 logit regressions. The dependent variable is a dummy variable indicating whether an individual purchased a car representing the given model in a given year. The same model (same make, other models) neighbor effect variable is the number of automobiles representing the same model (different models, same make) purchased by the 10 nearest neighbors in the last 10 days less one quarter the number of same model (different models, same make) purchases among the neighbors ranked $11^{\text {th }}$ through $50^{\text {th }}$ in nearness in the last ten days. The other makes neighborhood effect is computed as in Panel A. The control variables in both panels are the same as in Table 2, but their coefficients are omitted for brevity.

Panel A: Effects of the similarity of make only on neighbor influence

\begin{tabular}{|c|c|c|c|c|}
\hline \multirow[b]{2}{*}{ Make } & \multicolumn{2}{|c|}{ Coefficients } & \multicolumn{2}{|c|}{$t$-values } \\
\hline & Same make & Other makes & Same make & Other makes \\
\hline Opel & 0.379 & 0.145 & 7.07 & 4.70 \\
\hline Toyota & 0.516 & 0.131 & 10.31 & 4.28 \\
\hline Ford & 0.410 & 0.106 & 6.30 & 2.99 \\
\hline Nissan & 0.479 & 0.068 & 7.54 & 1.89 \\
\hline Volkswagen & 0.232 & 0.012 & 3.02 & 0.29 \\
\hline Volvo & 0.374 & 0.101 & 4.26 & 2.43 \\
\hline Peugeot & 0.308 & 0.077 & 3.11 & 1.72 \\
\hline Renault & 0.570 & 0.094 & 5.70 & 2.00 \\
\hline Mazda & 0.456 & 0.081 & 3.75 & 1.56 \\
\hline Fiat & 0.391 & 0.090 & 2.92 & 1.68 \\
\hline Citroen & 0.473 & 0.031 & 3.03 & 0.50 \\
\hline Mercedes Benz & 0.532 & -0.013 & 3.54 & -0.21 \\
\hline Honda & 0.807 & 0.097 & 4.80 & 1.48 \\
\hline Saab & 1.078 & 0.217 & 6.94 & 3.47 \\
\hline Mitsubishi & -0.289 & 0.014 & -0.84 & 0.18 \\
\hline Average & 0.448 & 0.083 & & \\
\hline Median & 0.456 & 0.090 & & \\
\hline
\end{tabular}




\section{Panel B}

The effects of the similarity of make and model on neighbor influence

\begin{tabular}{|c|c|c|c|c|c|c|}
\hline \multirow[b]{2}{*}{ Make and model } & \multicolumn{3}{|c|}{ Coefficients } & \multicolumn{3}{|c|}{$t$-values } \\
\hline & Same model & $\begin{array}{l}\text { Same make, } \\
\text { different model }\end{array}$ & Other makes & Same mode & $\begin{array}{l}\text { Same m } \\
\text { different } n\end{array}$ & her makes \\
\hline Toyota Corolla & 0.677 & 0.429 & 0.159 & 7.95 & 4.51 & 3.77 \\
\hline Opel Astra & 0.330 & 0.088 & 0.042 & 2.54 & 0.77 & 0.79 \\
\hline Volkswagen Golf & 0.350 & 0.149 & -0.009 & 2.14 & 0.98 & -0.15 \\
\hline Opel Vectra & 0.818 & 0.406 & 0.223 & 4.81 & 3.29 & 3.60 \\
\hline Nissan Primera & 0.858 & 0.216 & -0.023 & 5.33 & 1.49 & -0.33 \\
\hline Ford Escort & 0.703 & 0.505 & 0.221 & 3.24 & 3.47 & 3.24 \\
\hline Nissan Almera & 0.681 & 0.513 & 0.075 & 3.34 & 3.69 & 1.05 \\
\hline Mazda 323 & 0.743 & 0.620 & 0.112 & 3.44 & 2.82 & 1.52 \\
\hline Toyota Avensis & 0.716 & 0.432 & 0.070 & 3.25 & 3.22 & 0.93 \\
\hline Mazda 626 & 0.328 & 0.074 & 0.048 & 1.19 & 0.27 & 0.61 \\
\hline Average & 0.620 & 0.343 & 0.092 & & & \\
\hline Median & 0.692 & 0.418 & 0.072 & & & \\
\hline
\end{tabular}


Figure 1

The joint effect of time and distance rank on neighbor influence

Figure 1 plots 135 time-distance variable coefficients for the logit regressions of neighbor influence described in Table 2. The dependent variable in all regressions is a dummy variable indicating whether an individual purchased a car in a given year. Each time-distance variable is computed as the number of cars purchased by the neighbors at that distance rank and time interval. There are nine distance rank intervals and fifteen time intervals. Distance intervals denoted by numbers 1 thru 5 represent the number of purchases of each of the five nearest neighbors (usually zero or one), whereas intervals 6-10, 11-50, 51-200, and 201-500 represent the collective number of purchases of 5-300 neighbors, depending on the interval. Time intervals $t_{1}-t_{2}$ refer to the number of purchases by a particular group of neighbors between $t_{1}$ calendar days ago and $t_{2}$ calendar days ago. A single number means that $t_{1}$ equals $t_{2}$. Panel A plots the coefficients for the whole sample, Panel B for individuals living in urban communities, Panel $\mathrm{C}$ for individuals living in suburban communities, and Panel D for individuals living in rural communities. The coefficients for the control variables are reported in Panel A of Table 2.

Panel A: Whole sample

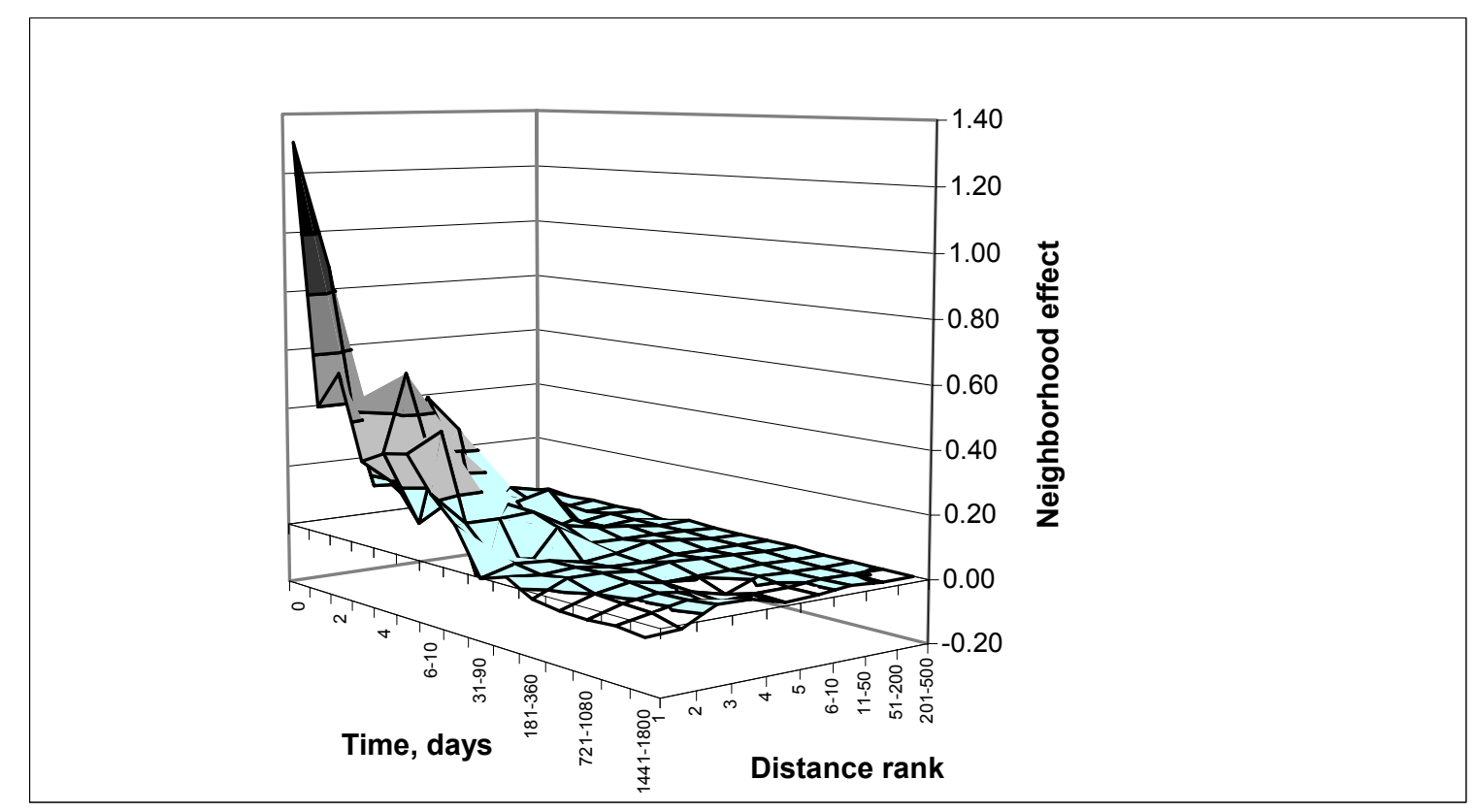


Panel B: Urban communities

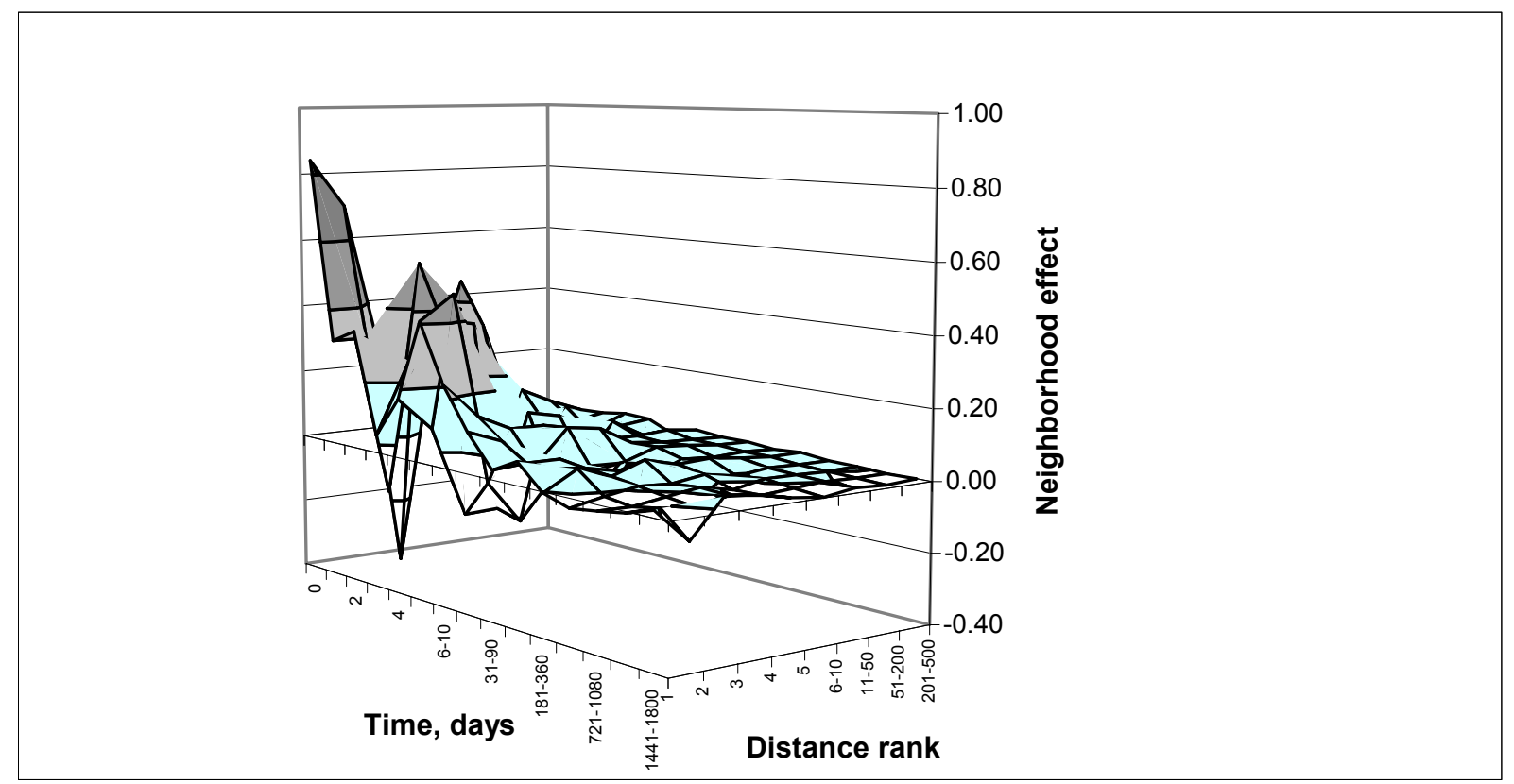

Panel C: Suburban communities

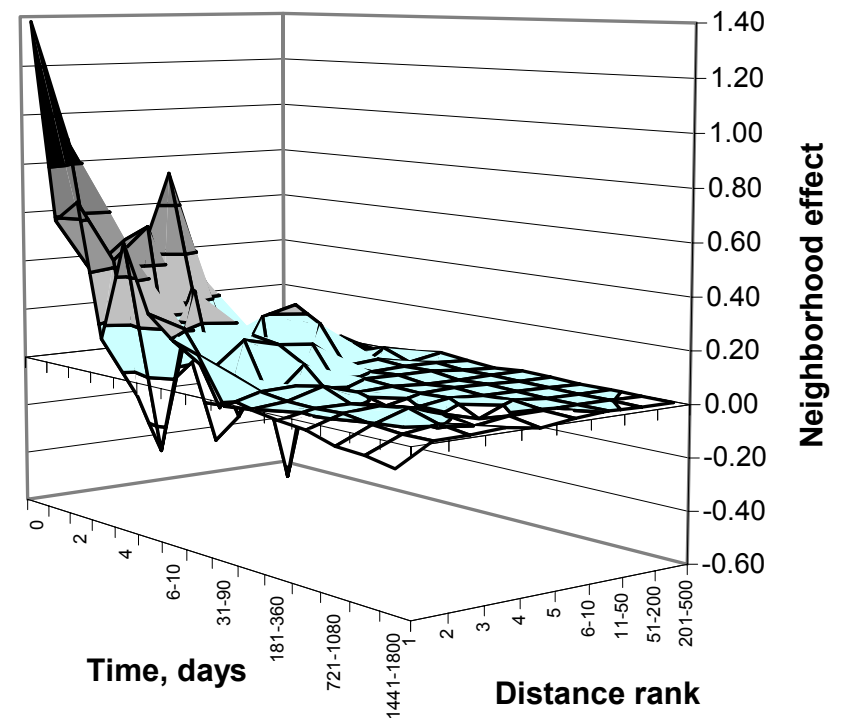


Panel D: Rural communities

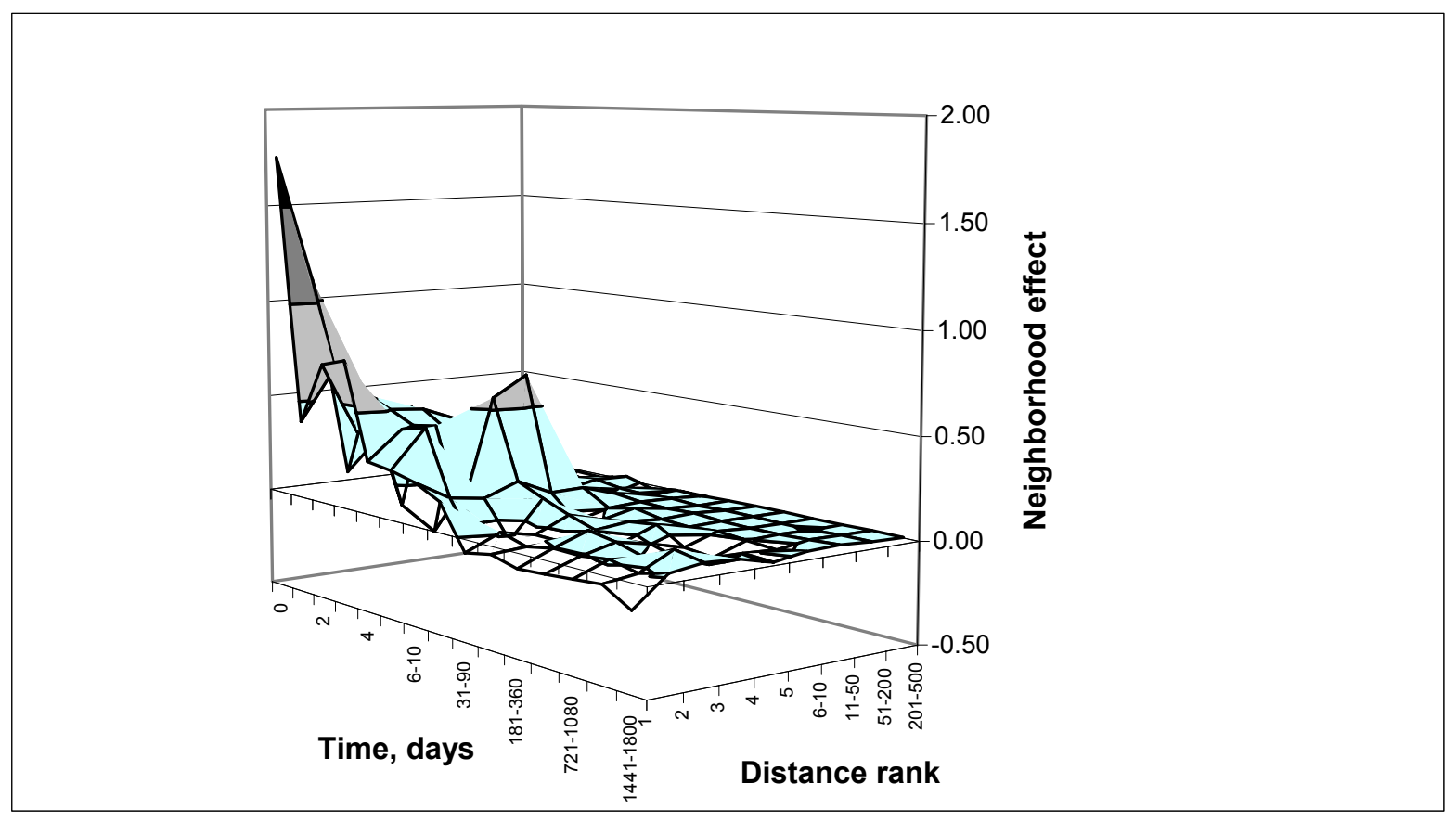


Figure 2

The effect of social class on neighbor influence

Figure 2 plots the neighbor effect coefficients and their 95\% upper and lower bounds for each social class. The results are obtained from ten logit regressions where each regression is restricted to only those individuals belonging to the social class. The dependent variable in all regressions is a dummy variable indicating whether an individual purchased a car in a given year. The neighbor effect is the number of automobiles purchased by the 10 nearest neighbors in the last 10 days less one quarter the number of purchases among the neighbors ranked $11^{\text {th }}$ through $50^{\text {th }}$ in nearness in the last ten days. A subject's social class decile is based on the sum of labor and capital income. The control variables are the same as in Table 2, but their coefficients are omitted for brevity.

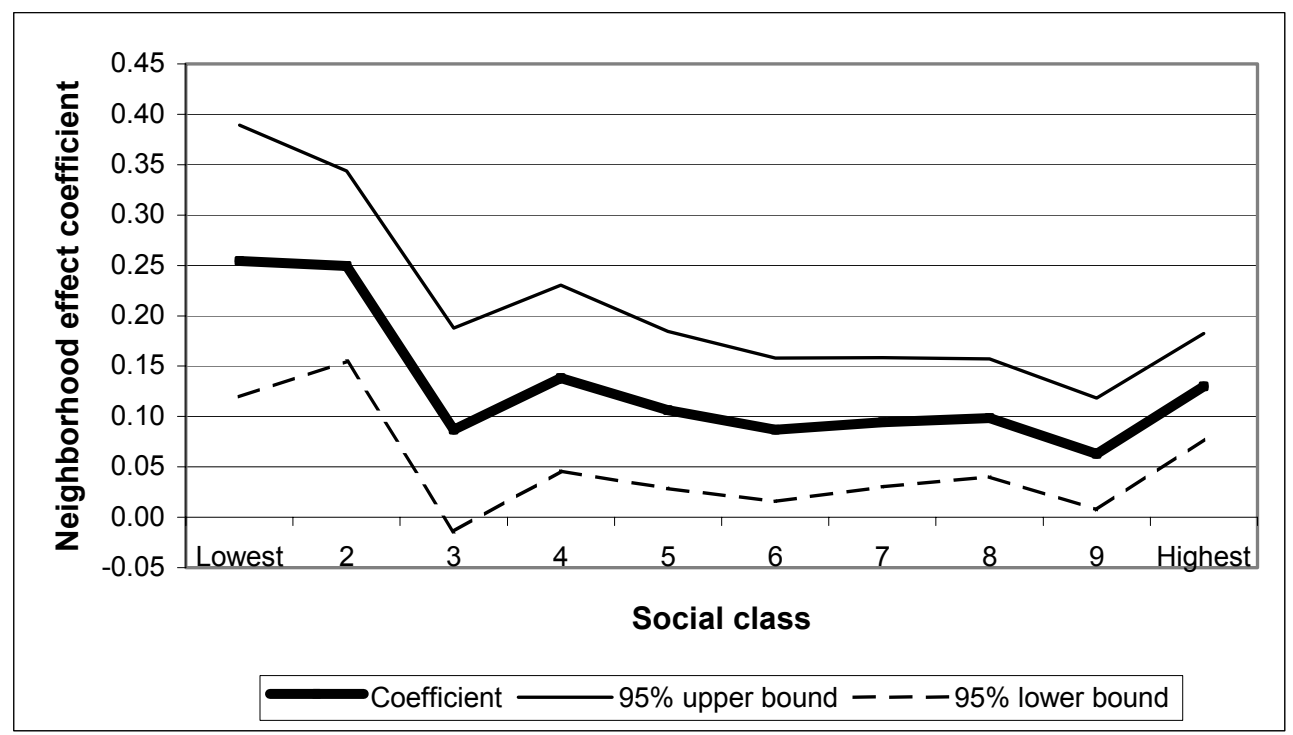


Figure 3

The effect of social class difference on neighbor influence

Figure 3 plots the neighbor effect coefficients from Model 4 in Table 3 along with their 95\% upper and lower bounds. The results are obtained from a logit regression where the dependent variable in all regressions is a dummy variable indicating whether an individual purchased a car in a given year. The neighbor effect is the number of automobiles purchased by the 10 nearest neighbors in the last 10 days less one quarter the number of purchases among the neighbors ranked $11^{\text {th }}$ through $50^{\text {th }}$ in nearness in the last ten days. A subject's social class decile is based on the sum of labor and capital income. The control variables are the same as in Table 2, but their coefficients are omitted for brevity.

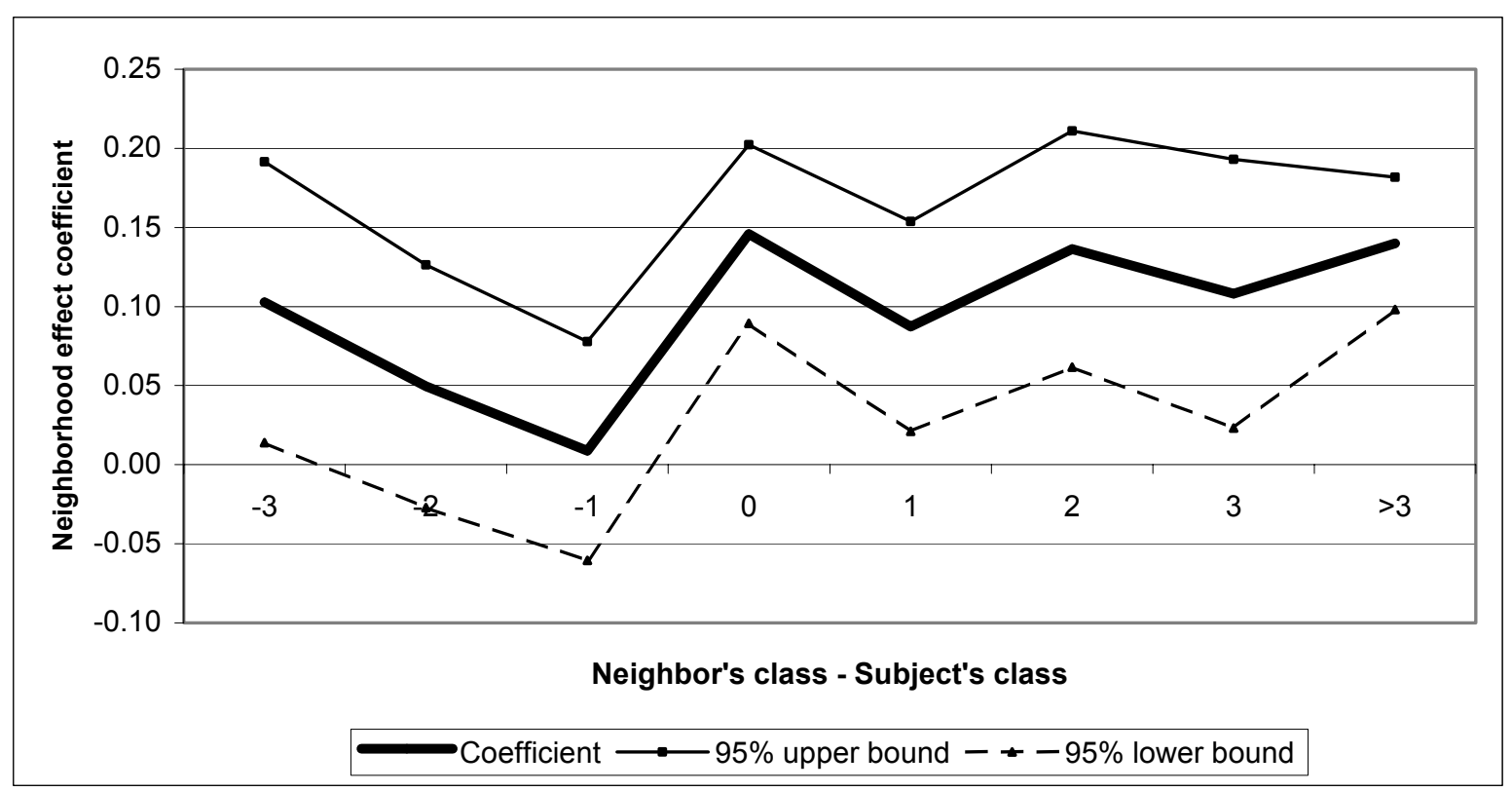

